\title{
Low intensity conflict
}

C. WILLIAM DECKNER, NASHVILLE VA HOSPITAL AND VANDERBILT UNIVERSITY SCHOOL OF MEDICINE, DEPARTMENT OF PSYCHIATRY, Nashville, Tenn. 37203

Two experiments were designed to demonstrate the effect of low intensity conflict on cognitive-motor performance. Ss working for small positive reinforcers were periodically required to make decisions under conditions of uncertainty. It was found that the performance of more highly motivated Ss was significantly impaired by a signal which required a decision. Results were related to previous studies on conflict.

Lazarus \& Deese (1952) point out that an understanding of the effects of conflict and stress on skilled performance "is of great theoretical and practical importance," and there are a number of studies which show that very obvious forms of stress (e.g., extremely loud noise) are detrimental to performance. There is less evidence, however, of the effects of more subtly distracting conditions. The latter are of interest in that they may be more representative of the circumstances under which individuals usually work in real life.

The present study is concerned with conditions which elicit relatively low intensity conflict. Two experiments were designed to determine if requiring Ss to make a decision under conditions of uncertainty constitutes a cognitive-motor conflict (Epstein \& Smith, 1967; Johnson, 1963) of sufficient intensity to impair performance. Relevant to the question of intensity of conflict is the variable of motivation. Andreas (1958) suggests that equality in strength of opposing tendencies alone is not a sufficient condition for conflict; some minimal absolute level of motivation is also necessary. In fact, Andreas presents evidence that intensity of conflict is more closely related to the absolute strength of the competing tendencies than to their approximation of equality in strength. The effect of level of motivation was investigated by varying type of reward and instructions.

While previous studies have shown that requiring Ss to make a difficult decision may disrupt concurrent behavior (Johnson, 1963), usually some form of punishment (e.g., electric shock) has been administered when the decision was not correct. Such avoidance learning situations seem likely to induce relatively high intensity conflict. The present study seeks to demonstrate the effect of conflict when Ss play a game for small positive reinforcers.

\section{EXPERIMENT 1}

Procedure. The Ss could earn a small reward for each opening of one combination lock (the "no risk lock") or win or lose larger rewards for each opening of a different lock (the "gamble lock"). In the first experiment, 10 eighth grade boys worked for pennies and 10 worked for points. The amount that could be earned for each opening of the no risk lock was one penny or point. The number of pennies or points which could be won for each opening of the gamble lock was seven, for each of eight trials. The amount which could be lost for each opening of the gamble lock was three on the first trial and increased by one on each of the following trials. Thus, on the second trial, the potential penalty was four; on the third trial, five; and by the eighth trial, 10 pennies or points could be lost with each opening of the gamble lock. While the amount of the potential loss was thus varied, the probability of winning or losing on each opening of the gamble lock was always the same: .50 .

The $S$ was informed of the amounts that could be won and lost by gambling before each trial. The combinations of both locks were visible to $S$ at all times, and he was permitted to practice opening each lock several times before the game began. The task of opening combination locks was chosen because it is difficult enough to require attention and concentration. It was, therefore, expected to be sensitive to experimentally induced distraction effects.

A small light on the table at which $S$ worked alternated on and off every $30 \mathrm{sec}$ of each $4 \mathrm{~min}$ trial to signal when the gamble lock could be approached. When the light was off, $S$ had no choice as only the no risk lock was operable; when the light was on, $S$ had to decide whether it was $t o$ his advantage to gamble or to continue operating the no risk lock.
The light-on condition was hypothesized to elicit conflicting tendencies to approach and avoid the gamble lock. On the early trials, when the amount of the potential loss was relatively small, Ss were expected to approach the gamble lock as soon as the light was turned on. By the eighth trial, when the amount which could be lost exceeded the amount which could be won, Ss were expected to continue working at the no risk lock even during the intervals when the light was on.

Results. To avoid measuring time in shifting from one lock to the other and to avoid possible differences in difficulty in opening the two locks, the dependent measure was restricted to those trials (later in the sequence) during which Ss continued to operate the no risk lock even under the light-on condition. Each $S$ was used as his own control by comparing his performance under the light-on condition with that under the light-off condition. A t test for correlated observations was used to analyze the performances of the penny-rewarded and point-rewarded groups separately. The dependent variable is the number of openings of the no risk lock, and it was predicted there would be significantly fewer openings under the hypothesized conflict condition than under the no choice condition.

It was found that only with the Ss who worked for pennies was the prediction supported; differences were in the anticipated direction and significant $(p<.025)$. With the Ss who worked for points, there was no difference in performance between the light-on and light-off conditions.

\section{EXPERIMENT 2}

Procedure. The procedure of Experiment 2 was essentially the same as that of Experiment 1. Differences were that two groups of college students were employed, both groups were rewarded with points, and instructions were varied. One group of 15 male college students was given instructions which implied their performance reflected on their judgment. A second group of 15 was given instructions which suggested the experiment could be regarded as a game. The difference in instructions was assumed to motivate the first group more than the second.

Results and Discussion. It was found that the conflict condition resulted in a significant $(p<.01)$ decrement in performance for the group which was given the more highly motivating instructions. This constitutes a replication with a different population and a different type of motivator of the finding with the eighth grade students who were rewarded with pennies. With the less highly motivated college students, the difference in performance between the conflict and no choice conditions approached, but did not reach, statistical significance.

Apparently, even low intensity conflict has significantly detrimental effects on a performance which is susceptible to error without close attention and concentration. Because of its ambiguous meaning, rather than extreme physical properties, the small light constituted a potent distractor for the Ss who were more highly motivated. As this was the case only with the more highly motivated groups, Andreas' suggestion (1958), that the strength of competing tendencies must reach some minimal absolute level for conflict to result, appears to be supported.

The results of this study also tend to substantiate Johnson's (1963) interpretation that the decision-making process plays a central role in conflict. The present study complements the findings of Johnson, whose procedure involved the administration of punishment, by demonstrating the effect of conflict independent of a punishment contingency.

\section{REFERENCES}

ANDREAS, B. G. Motor conflict behavior as a function of motivation and amounts of training. J. exp. Psychol., 1958, 55, 173-178.

EPSTEIN, S., \& SMITH, B. Modes and adequacy of resolution of three basic types of cognitive-motor conflict. J. exp. Psychol., 1967, 74, 264-271.

JOHNSON, H. J. Decision making, conflict, and physiological arousal. $J$. abnorm soc. Psychol., 1963, 67, 114-124.

LAZARUS, R. S., \& DEESE, J. The effects of psychological stress upon performance. Psychol. Bull., 1952, 49, 293-315. 